\title{
Caring for Elderly Immigrants: Is it Possible to have Equal Opportunities?
}

\section{Natalie Figueredo-Borda}

Faculty of Nursing and Health Technologies, Catholic University of Uruguay, Uruguay

*Corresponding author: Natalie Figueredo-Borda, Catholic University of Uruguay, Faculty of Nursing and Health Technologies, Department of Nursing Sciences, Avenida Garibaldi 2831 Montevideo, Montevideo 11600, Uruguay, Tel: +59898615640; E-mail: nafiguer@ucu.edu.uy

Rec date: Jun 28, 2015; Acc date: Jul 20, 2015; Pub date: Jul 23, 2015

Copyright: (c) 2015 Figueredo-Borda N. This is an open-access article distributed under the terms of the Creative Commons Attribution License, which permits unrestricted use, distribution, and reproduction in any medium, provided the original author and source are credited.

\section{Introduction}

Immigration has exposed people to difficulties in accessing proper health care. Frequently enough institutions are not suited to fully accommodate patient's beliefs, cultural necessities, presenting different communication barriers, especially with older patients $[1,2]$.

This situation could increase the vulnerability of those patients, in particular those who require specific treatment or have special needs. According to the Health World Organization, in order to try to minimize social's differences, it is urgent that Nations around the world direct their public policies to include those specific needs, taking into account the most vulnerable groups [3-5]. Therefore, as a main concern, the elderly immigrants should be taken into special consideration. One of the causes that explain their precarious situation is the lack of health professionals trained in cultural sensibility, the absence of their family, as well as social, financial and institutional support to find qualified professionals $[5,6]$.

Considering this, Nurses and other health care professionals should be especially sensitive to this particular problematic by improving their different skills in order to be more efficient while caring for unprivileged patients, such as the elderly. This could be achieved by training the professionals in understanding the socio-cultural differences with their patients, which could lead to better results. [7].

These multicultural aspects that could affect the relationship with the patient, have been exposed by Nurses, who said that cultural diversity was challenging and frustrating, and that the most important difficulties were language, lack of training, cultural differences and little organizational support [8].

For health care professionals would be important to examine their personal and professional knowledge before approaching a patient and their families, different from their own culture, which would improve the attention's quality, especially in elderly patients. This would prevent some problems, such as cultural imposition and to help prevent the patient's lack of integrity [9].

Finally, it has to be said that the organization's involvement is crucial in order to train and help health care professionals to provide a more sensitive cultural treatment to elderly and international patients.

\section{References}

1. Hall K, Hardill I (2014) Retirement migration, the 'other'story: caring for frail elderly British citizens in Spain. Ageing and Society 1-24.

2. Aguila E, Fonseca R, Vega A (2015) Self-Employment, Health Insurance, and Return Migration of Middle-Aged and Elderly Mexican Males. In Challenges of Latino Aging in the Americas 103-119.

3. World Health Organization. Health in the post 2015 development agenda: need for a social determinants of health approach. Joint statement of the UN Platform on Social Determinants of Health.

4. World Health Organization (2013) Closing the health equity gap. Policy Options and Opportunities for action. NLM classification: WA 525.

5. Castro A, Ruiz E (2009) The effects of nurse practitioner cultural competence on Latina patient satisfaction. Journal of the American Academy of Nurse Practitioners 21: 278-286.

6. United Nations Educational, Scientific and Cultural Organization (2011) International Bioethics Committee (IBC). Draft Report of IBC on the Principle of Respect for Human Vulnerability and Personal Integrity.

7. Campinha-Bacote J (2008) Cultural desire: 'Caught'or 'taught'? Contemporary nurse 28:141-148.

8. Taylor RA, Alfred MV (2010) Nurses' perceptions of the organizational supports needed for the delivery of culturally competent care. Western journal of nursing research 32: 591-609.

9. Calvillo E, Clark L, Ballantyne JE, Pacquiao D, Purnell LD, et al. (2009) Cultural competency in baccalaureate nursing education. Journal of Transcultural Nursing 20: 137-145. 